\title{
Lightning Observatory in Gainesville (LOG), Florida: A Review of Recent Results
}

\author{
V.A. Rakov, S. Mallick, and A. Nag ${ }^{1}$ \\ Department of Electrical and Computer Engineering \\ University of Florida, Gainesville, Florida, USA \\ ${ }^{1}$ Presently with Vaisala, Inc., Tucson, Arizona, USA \\ E-mail: (rakov@ece.ufl.edu)
}

\begin{abstract}
The Lightning Observatory in Gainesville (LOG), Florida, was established in $\mathbf{2 0 0 4}$ primarily for measurements of electric and magnetic fields produced by lightning. More recently, an $x$-ray detector was added, and various optical instruments were used in different years. A number of new results have been obtained, most important of which are reviewed in this paper.
\end{abstract}

Keywords-lightning electromagnetic fields, cloud charge structure, preliminary breakdown, positive lightning, compact intracloud discharge, ionosphere, $x$-rays

\section{INTRODUCTION}

The Lightning Observatory in Gainesville (LOG), Florida, is part of the International Center for Lightning Research and Testing (ICLRT), which also includes the Camp Blanding (CB) lightning-triggering facility. The LOG was established on the University of Florida campus in 2004 primarily for measuring electromagnetic fields produced by lightning. Over the years the experimental setup has undergone upgrades, modifications, expansions, and relocation. It is currently located on the roof of the five-storey New Engineering Building (29 $38^{\prime} 32.27^{\prime \prime} \mathrm{N}$ $\left.82^{\circ} 20^{\prime} 49.70^{\prime \prime} \mathrm{W}\right)$. The LOG includes a glass cupola providing over a $180^{\circ}$ unobstructed view of the horizon. The cupola houses digitizing oscilloscopes and computers, with the sensors being located nearby on the roof. The system currently includes electric field measurements, electric field derivative $(\mathrm{dE} / \mathrm{dt})$ measurements, magnetic field derivative $(\mathrm{dB} / \mathrm{dt})$ measurements, and an x-ray detector. Signals from all the sensors are relayed by fiber-optic links to the glass cupola, where they are recorded. All records are GPS time stamped. An overview and a photograph of LOG are shown in Figs. 1(a) and $1(\mathrm{~b})$, respectively.

The LOG was originally designed to respond to both natural lightning flashes during local storms over Gainesville and natural and rocket-triggered flashes at $\mathrm{CB}$, at a distance of about $45 \mathrm{~km}$ from LOG. Accordingly, there are two modes of operation: single-station (for local measurements) and twostation (for recording $\mathrm{CB}$ events). For single-station measurements, the system is triggered when the electric field exceeds a set threshold level. For two-station measurements, a dedicated phone line is used to transmit a trigger signal from $\mathrm{CB}$ to $\mathrm{LOG}$ in the event of a lightning discharge at $\mathrm{CB}$. The single-station mode of operation was also used for recording distant (up to $350 \mathrm{~km}$ or so) flashes. In 2011, an additional field measuring station was set up in Starke, at a distance of about 3 $\mathrm{km}$ from $\mathrm{CB}$, to allow three-station (LOG, Starke, and $\mathrm{CB}$ ) measurements. Detailed descriptions of LOG are given by Nag (2010) [1] and Mallick et al. (2012a) [2].

The following selected topics studied at LOG are reviewed in this paper:

- Lower positive charge in the cloud and lightning type

- Positive lightning

- Compact intracloud lightning discharges

- Lightning interaction with the ionosphere

- X-rays produced by first and subsequent strokes in natural lightning

\section{LOWER POSITIVE CHARGE IN THE CLOUD AND LIGHTNING TYPE}

The percentage of flashes exhibiting detectable preliminary breakdown pulse trains varies from less than $20 \%$ to $100 \%$ (Nag and Rakov, 2009a) [3]. The largest pulses in the train can exceed in magnitude the following first return-stroke pulse (Nag and Rakov, 2009b) [4]. We interpret the preliminary breakdown (PB) pulse train as being generated when a negatively-charged channel extends downward from the main negative charge region and encounters an appreciable lower positive charge region (LPCR). When the LPCR is small no PB pulse train may be produced.

While the LPCR may serve to enhance the electric field at the bottom of the negative charge region and thereby facilitate the launching of a negatively-charged leader toward ground, presence of excessive LPCR may prevent the occurrence of negative cloud-to-ground flashes by "blocking" the progression of descending negative leader from reaching ground.

We infer, from our measurements at LOG, four conceptual lightning scenarios that may arise depending upon the magnitude of the LPCR, illustrated in Fig. 2. These and other results on the subject are presented by Nag and Rakov (2008, 2009a,b) [3-5]. 


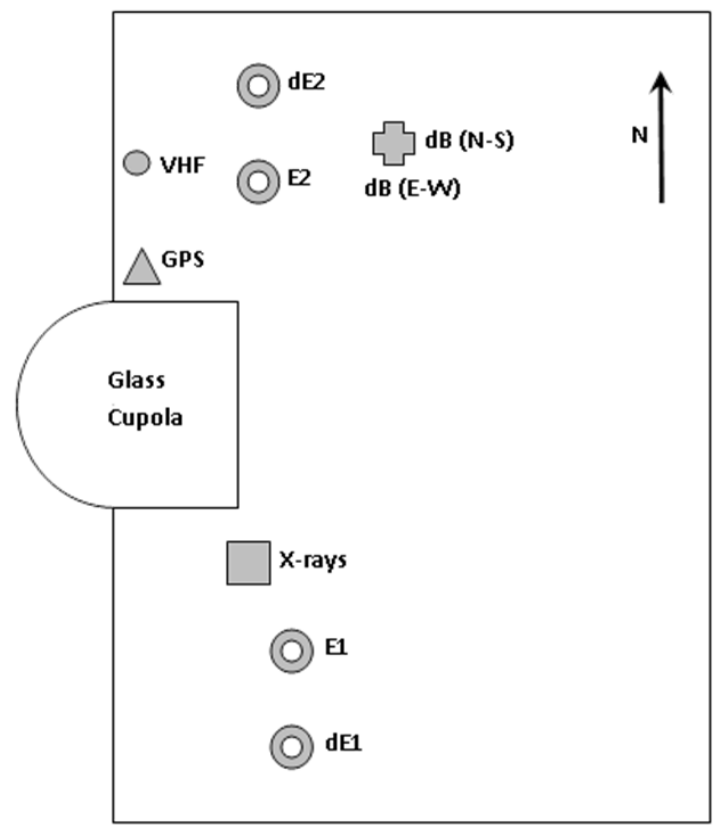

E1 and E2 - Wideband vertical electric field antennas $\mathrm{dE} 1$ and $\mathrm{dE} 2$ - Electric field derivative antennas $d B(N-S)$ and $d B(E-W)$ - Magnetic field derivative antennas (north-south and east-west components, respectively)

VHF - Narrowband ( $36 \mathrm{MHz}$ ) VHF radiation antenna $\mathrm{X}$-rays - NaI X-ray detector

(a)

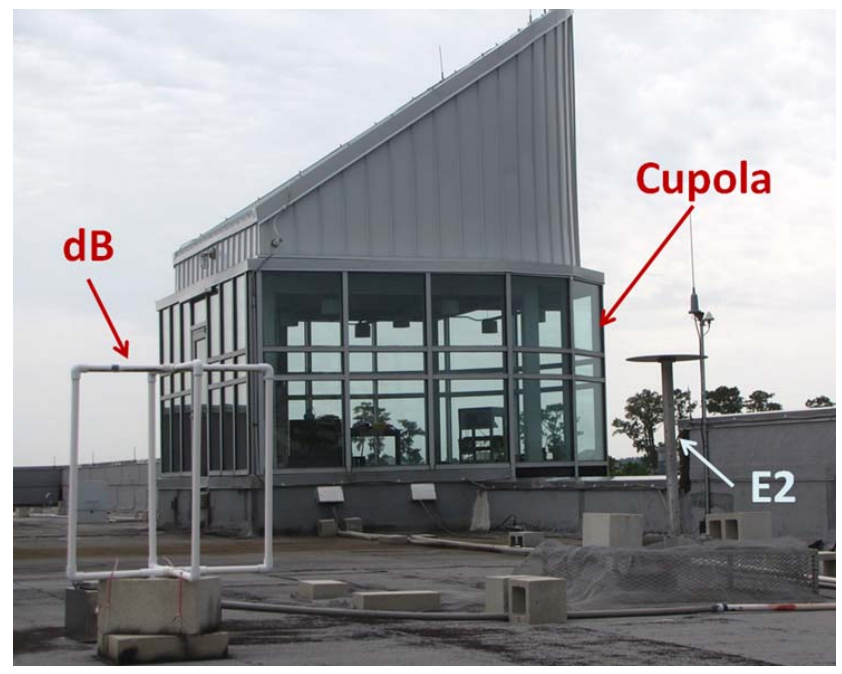

(b)

Figure 1. (a) An overview and (b) photograph (both for 2010) of the Lightning Observatory in Gainesville (LOG), Florida. E1, dE1, VHF, and xray detector were used in the single-station mode of operation, E2 and dE2 in the two-station mode, and $\mathrm{dB}$ in both modes. The VHF antenna is presently not utilized, and additional electric field and $\mathrm{dE} / \mathrm{dt}$ antennas were added in 2011 for very close lightning field measurements.

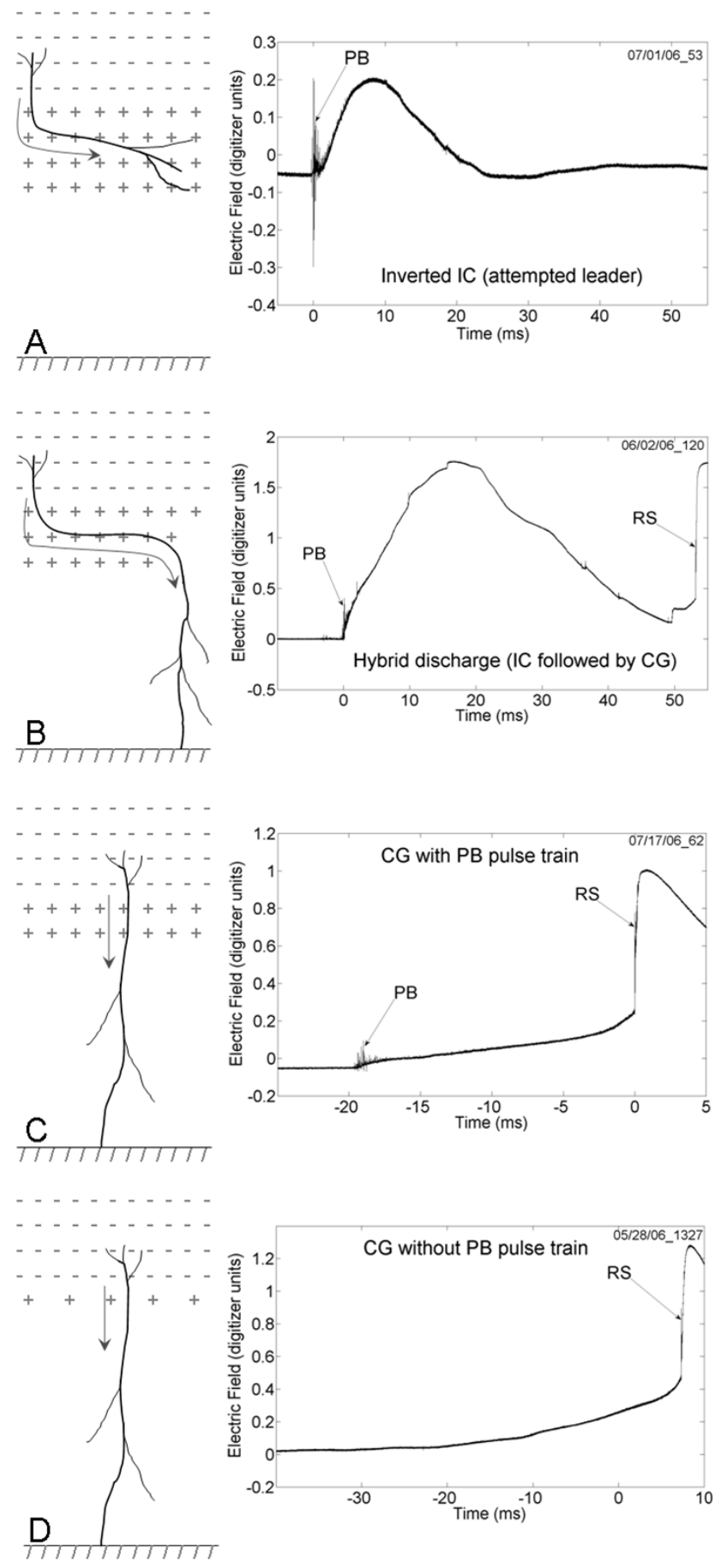

Figure 2. The left panels, A-D, schematically show four types of lightning that may arise depending upon the magnitude of the LPCR. The charge configuration in each of the scenarios represents only its vertical profile (no lateral boundaries are shown). Arrows indicate the direction of propagation of negative leader. The corresponding examples of expected electric field signatures are shown in the right panel. The field waveforms are from four different thunderstorms recorded at some tens of kilometers at LOG, using the same instrumentation with a decay time constant of $10 \mathrm{~ms} . \mathrm{PB}=$ preliminary breakdown pulse train, RS = return-stroke waveform. Adapted from [4]. 


\section{Positive LightNing}

It appears that at least six different scenarios (see Fig. 3) can give rise to downward positive lightning. For four of them, (a) tilted positive dipole, (b) positive monopole, (c) inverted dipole, and (d) unusually large lower positive charge region, the primary source of charge is a charged cloud region, while for the other two, (e) negative in-cloud leader channel cut-off and (f) branching of in-cloud channel, the primary source of charge is an in-cloud lightning channel formed prior to the positive discharge to ground. Out of 52 positive strokes observed in 2007-2008 at LOG, $81 \%$ were not preceded by incloud discharge activity and, hence, were not of type (e) or (f).
Positive flashes are usually composed of a single stroke, although up to four strokes per flash were observed. Similar to negative lightning, subsequent strokes in positive flashes have been observed to occur both in a new and in the previouslyformed channel (see Table I). Out of the 52 positive cloud-toground flashes observed at LOG, 42 (81\%) were single-stroke, $9(17 \%)$ two-stroke, and $1(2.0 \%)$ three-stroke flashes. We inferred that 3 subsequent strokes in our data likely followed the previously-created (first-stroke) channel and 5 likely created new ground terminations.

These and other results on positive lightning are presented by Nag and Rakov (2012) [6].

TABle I. OCCurrence of Subsequent Strokes in Positive Flashes that Follow a Previously-Created Channel. AdaPted From [6].

\begin{tabular}{|l|c|c|c|c|}
\hline \multicolumn{1}{|c|}{ Reference } & Location & $\begin{array}{c}\text { Occurrence (percentage) of } \\
\text { subsequent strokes in a } \\
\text { previously-created channel }\end{array}$ & $\begin{array}{c}\text { Sample size (total } \\
\text { number of subsequent } \\
\text { strokes) }\end{array}$ & Remarks \\
\hline $\begin{array}{l}\text { Ishii et al. } \\
(1998) \text { [7] }\end{array}$ & Japan & $0(0 \%)$ & 17 & $\begin{array}{c}\text { Winter storms; five-station electric field } \\
\text { records }\end{array}$ \\
\hline $\begin{array}{l}\text { Fleenor et al. } \\
(2009) \text { [8] }\end{array}$ & $\begin{array}{c}\text { U.S. Central Great Plains } \\
\text { (Kansas and Nebraska) }\end{array}$ & $5(56 \%)$ & 9 & $\begin{array}{c}\text { Summer storms; video records, electric } \\
\text { field records (LASA), NLDN }\end{array}$ \\
\hline $\begin{array}{l}\text { Saba et al. } \\
(2010) \text { [9] }\end{array}$ & Brazil, Arizona, Austria & $1(4.8 \%)$ & 21 & $\begin{array}{c}\text { Probably summer storms; high-speed } \\
\text { video records, lightning }\end{array}$ \\
\hline $\begin{array}{l}\text { Nag and } \\
\text { Rakov } \\
(2012) \text { [6] }\end{array}$ & Florida & $3(38 \%)$ & 8 & $\begin{array}{c}\text { Summer (2 flashes) and winter (1 flash) } \\
\text { storms; electric field records, NLDN }\end{array}$ \\
\hline
\end{tabular}

LASA $=$ Los Alamos Sferic Array

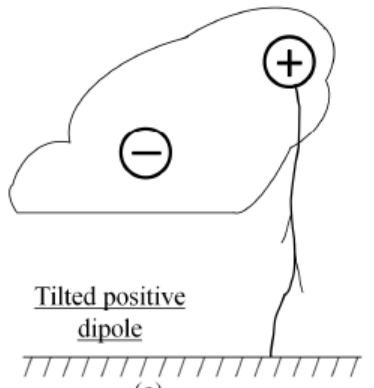

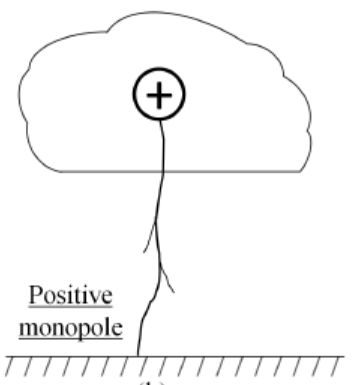

(b)

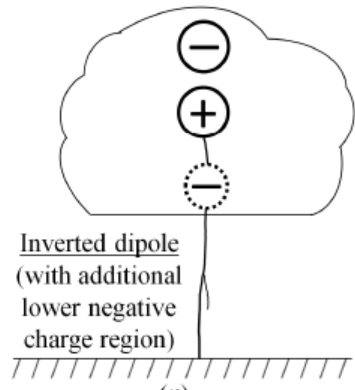

(c)

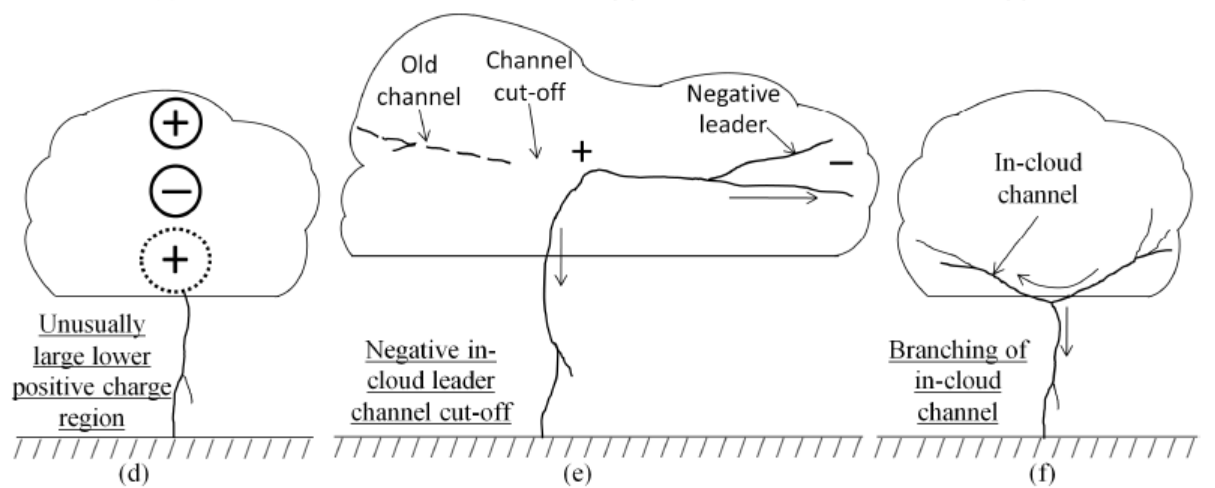

(d)

(f)

Figure 3. Conceptual cloud-charge-configurations/scenarios leading to production of downward positive lightning. Adapted from [6]. 


\section{COMPACT INTRACLOUD LIGHTNING DISCHARGES}

Compact intracloud lightning discharges (CIDs), which were first reported by Le Vine (1980) [10], received their name (Smith et al., 1999) [11] due to their relatively small (hundreds of meters) spatial extent. They

- $\quad$ are most intense natural producers of HF-VHF (3 - 300 $\mathrm{MHz}$ ) radiation on Earth,

- tend to occur at high altitudes (mostly above $10 \mathrm{~km}$ ),

- appear to be associated with strong convection, however, even the strongest convection does not always produce CIDs,

- tend to produce less light than other types of lightning discharges,

- produce single bipolar electric field pulses (Narrow Bipolar Pulses or NBPs) having typical amplitudes of the order of $10 \mathrm{~V} / \mathrm{m}$ at $100 \mathrm{~km}$, which is comparable to or higher than for return strokes in ground flashes.

Electromagnetic signatures of CIDs are shown in Fig. 4 and an example of CID occurring prior to a cloud-to-ground discharge is shown in Fig. 5. From the electromagnetic point of view, the CID is essentially a bouncing-wave phenomenon.
Electrical parameters for 48 CIDs, inferred using the Hertzian dipole approximation, are given in Table II. CID peak currents are comparable to or higher than those for first return strokes in cloud-to-ground lightning, while their peak radiated (wideband) power is about an order of magnitude larger than that for return strokes.

TABLE II. ElECtRICAl PARAMETERS OF CIDS. AdAPTED FROM [14].

\begin{tabular}{|l|c|c|c|c|c|}
\hline & $\begin{array}{c}\text { Peak } \\
\text { Current } \\
(\mathbf{k A})\end{array}$ & $\begin{array}{c}\text { Zero-to-Peak } \\
\text { Current } \\
\text { Risetime }(\boldsymbol{\mu s})\end{array}$ & $\begin{array}{c}\text { Charge } \\
\text { Transfer } \\
\text { at 5 } \mathbf{\mu s} \\
\mathbf{( m C )}\end{array}$ & $\begin{array}{c}\text { Peak } \\
\text { Power } \\
(\mathbf{G W})\end{array}$ & $\begin{array}{c}\text { Energy } \\
\text { at 5 } \boldsymbol{\mu s} \\
\mathbf{( k J )}\end{array}$ \\
\hline GM & 74 & 5.0 & 164 & 29 & 31 \\
\hline Min & 33 & 2.3 & 22 & 9.6 & 4.0 \\
\hline Max & 259 & 9.5 & 496 & 124 & 146 \\
\hline
\end{tabular}

These and other results on CIDs are presented by Nag and Rakov (2009c, 2010a,b) [12-14] and Nag et al. (2010, 2011) $[15,16]$.
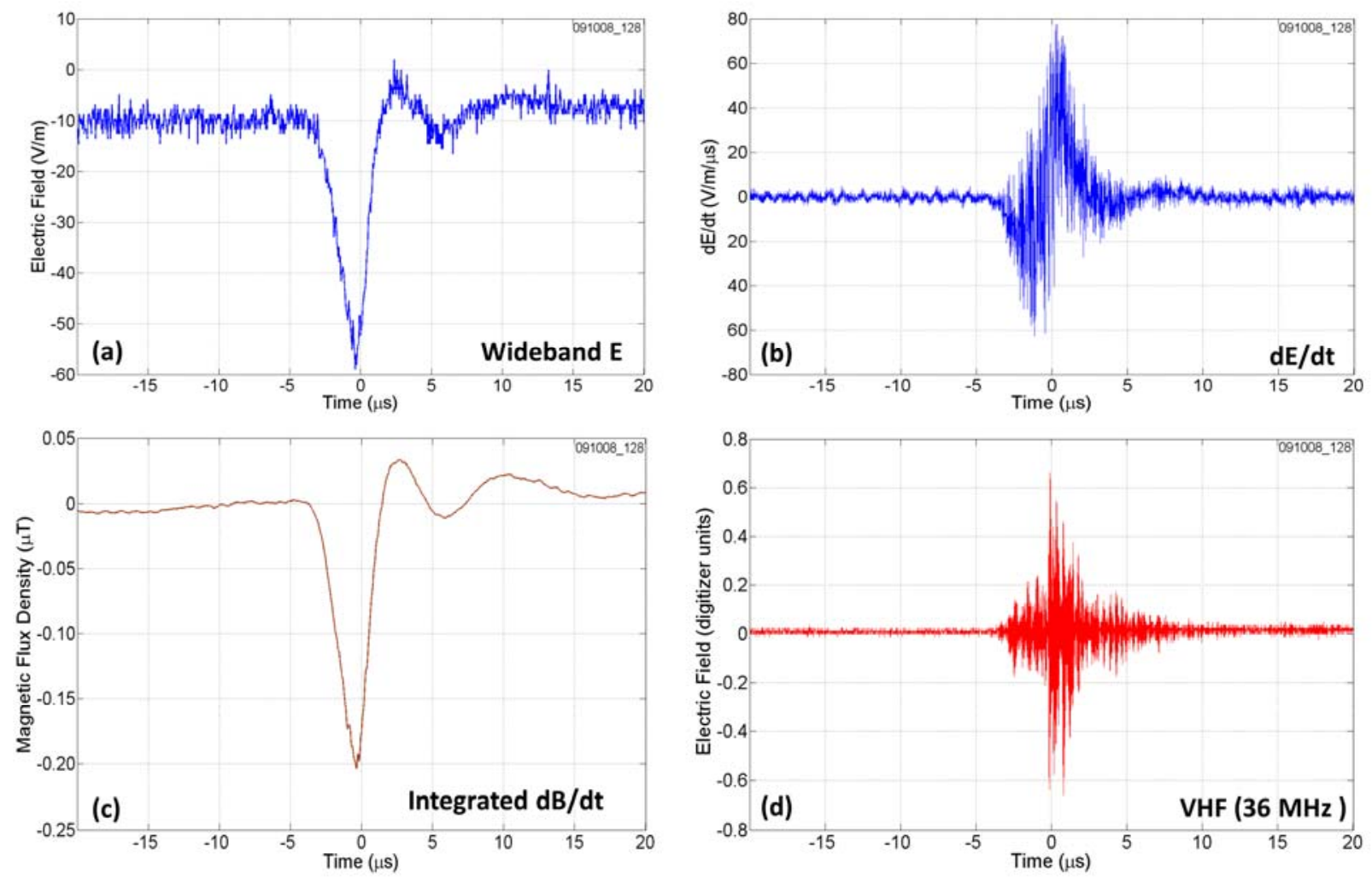

Figure 4. (a) Wideband electric field, (b) electric field derivative (dE/dt), (c) integrated magnetic field derivative (dB/dt), and (d) narrowband VHF (36 MHz) radiation burst produced by a CID in Gainesville, FL. From $\mathrm{E}_{\mathrm{z}} / \mathrm{B}_{\varnothing}=2.24 \times 10^{8} \mathrm{~m} / \mathrm{s}$ and $\mathrm{r}=17.2 \mathrm{~km}$, the source height $\mathrm{h}=15 \mathrm{~km}$. Adapted from [15]. 


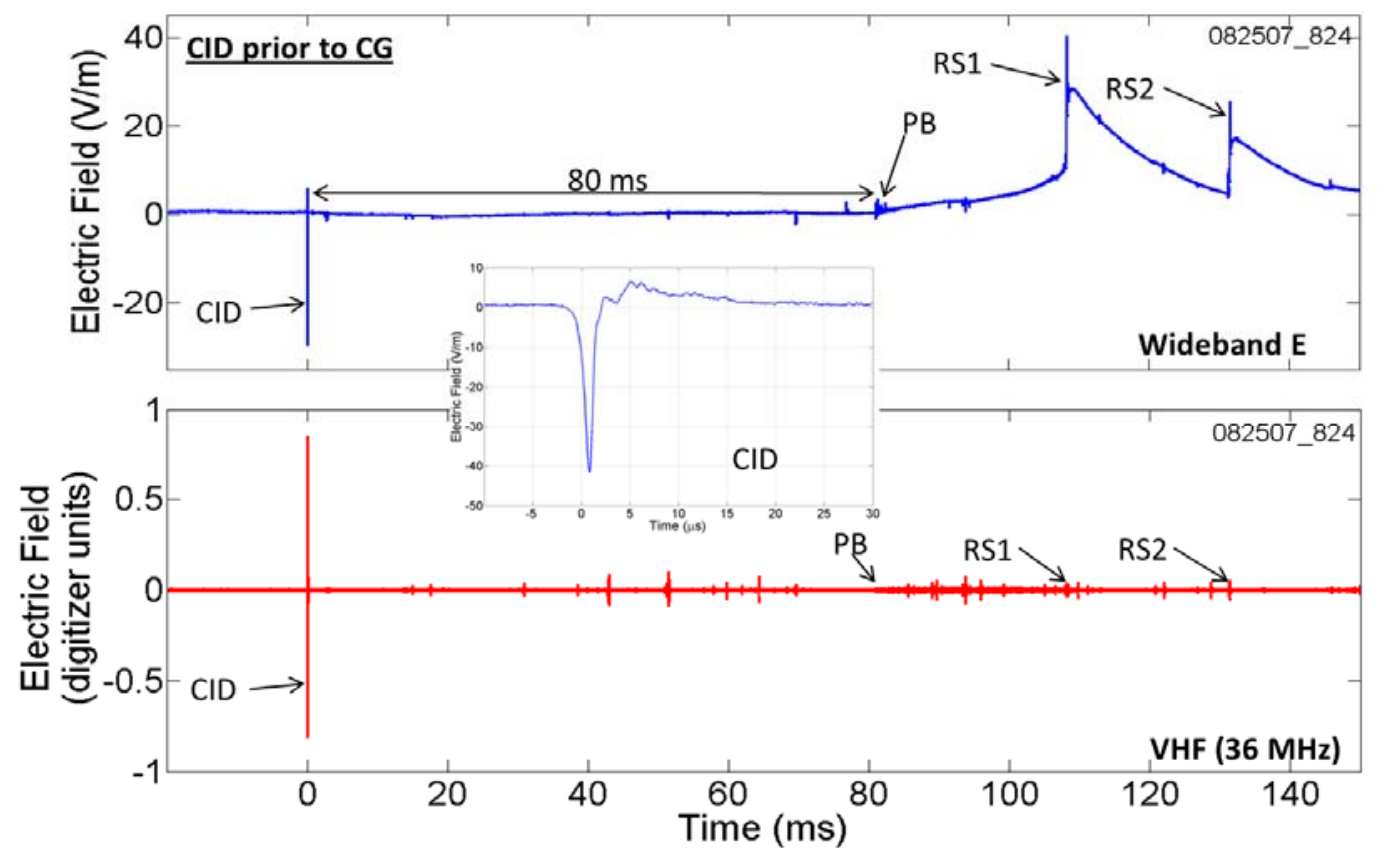

Figure 5. Electric field and VHF (36 MHz) radiation from a CID that was followed ( $80 \mathrm{~ms}$ later) by the preliminary breakdown of a multiple-stroke cloud-toground discharge. Inset shows the CID signature on an expanded ( $5 \mu$ s per division) timescale. No NLDN locations are available.

\section{LIGHTNING INTERACTION WITH THE IONOSPHERE}

We analyzed wideband vertical electric field waveforms of 265 first and 349 subsequent return strokes in negative natural lightning in Florida. The NLDN-reported distances ranged from 10 to $330 \mathrm{~km}$. At distances greater than $100 \mathrm{~km}$ or so, electric field waveforms, recorded at LOG under primarily daytime conditions, tend to be oscillatory (see Fig. 6).

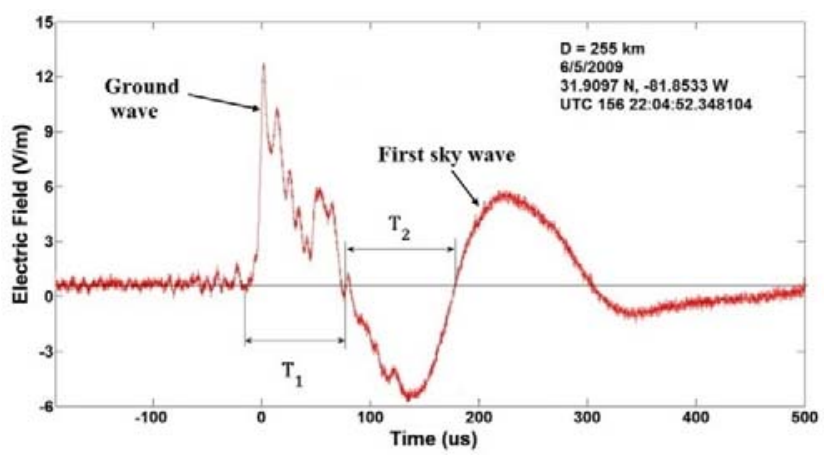

Figure 6. Vertical electric field waveform of a negative first return stroke shown on a $700-\mu$ s time scale. The electric field waveform is dominated by its radiation component. Shown are the initial half-cycle duration or zerocrossing time $\left(\mathrm{T}_{1}\right)$ and the opposite polarity overshoot duration $\left(\mathrm{T}_{2}\right)$. Adapted from [17].

We interpreted the initial positive half-cycle and the opposite-polarity overshoot of observed electric field waveforms as the ground wave and the second positive halfcycle as the one-hop ionospheric reflection (first sky wave), which is confirmed by FDTD modeling results presented in Fig. 7. The observed difference in arrival times of these two waves for subsequent strokes is considerably smaller than for first strokes, suggesting that the first-stroke electromagnetic field caused a descent of the ionospheric D-layer, so that the electromagnetic signal of a subsequent stroke is reflected at an appreciably lower height (see Table III).

The ionosphere reflecting height, $\mathrm{h}_{1}$, for the first sky wave was calculated using the following equation (e.g., Laby et al., 1940) [18]:

$$
h_{1}=R_{e}\left[\cos ^{2}\left(\frac{r}{2 R_{e}}\right)-1\right]+\sqrt{\left\{R_{e}^{2}\left[\cos ^{2}\left(\frac{r}{2 R_{e}}\right)-1\right]+\left(\frac{c t_{1}+r}{2}\right)^{2}\right\}}
$$

where $R_{e}=6367 \mathrm{~km}$ is the mean radius of the Earth, $r$ is the distance to the lightning channel, $\mathrm{t}_{1}$ is the difference in arrival times of the first sky wave and the ground wave, and $\mathrm{c}$ is the speed of light. As a first approximation, we assumed that $\mathrm{t}_{1}=\mathrm{T}_{1}+\mathrm{T}_{2}$ (see Fig. 6).

Lightning-driven mechanisms that are known to perturb the ionosphere are elves expanding over a radial distance of up to a few hundred kilometers across the bottom of the ionosphere, halos occurring below elves altitudes, and sprites, extending between 40 and $90 \mathrm{~km}$ heights and often having faint tendrils extending from $50 \mathrm{~km}$ or so to altitudes as low as $20 \mathrm{~km}$ (near the cloud tops). The discharges analyzed here are of negative polarity and thus very likely not to have created sprites. Lightning interactions with the ionosphere are relatively brief (for example, optical elves typically last less than $1 \mathrm{~ms}$ ), but their effects can persist for 10-100 s (e.g., Inan et al., 2010 [19]), which is much longer than the duration of causative lightning flash. Elves and halos are known to create ionospheric height perturbations of several kilometers during 
nighttime conditions (Inan et al., 2010 [19]), which is smaller than the mean value of $11 \mathrm{~km}$ inferred in this study for all subsequent strokes (see Table III), but comparable to that of 5 $\mathrm{km}$ for the majority $(83 \%)$ of those strokes. It should be emphasized that the previously studied lightning perturbations are almost exclusively for nighttime conditions, because of the visibility of the associated optical emissions. To our knowledge, localized lightning-driven ionospheric perturbations have not been studied under daytime conditions. The magnitude of the apparent height changes found in our study is rather large, but this could be due to cumulative contributions of multiple strokes to lowering the ionospheric reflection height.

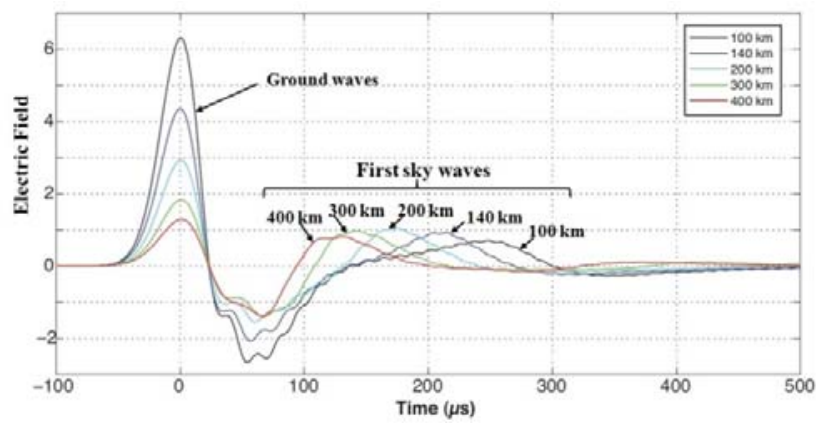

Figure 7. Simulated vertical electric field waveforms (up to about $30 \mathrm{kHz}$ ) at distances ranging from 100 to $400 \mathrm{~km}$. The second positive half-cycle, occurring at earlier times as the distance increases, is a reflection from the simulated daytime ionosphere. Adapted from [17].

TABLE III. Mean VAlues of $t_{1}$ And $h_{1}$ For First And SubSEQuent STROKES. ADAPTED FROM [17].

\begin{tabular}{|l|c|c|}
\hline \multirow{2}{*}{} & \multicolumn{2}{|c|}{ Mean values } \\
\cline { 2 - 3 } & $\boldsymbol{t}_{\boldsymbol{1}} \approx \boldsymbol{T}_{\boldsymbol{1}}+\boldsymbol{T}_{\boldsymbol{2}}$ & $\boldsymbol{h}_{\boldsymbol{1}}$ \\
\hline First strokes $(\mathrm{n}=108)$ & $200 \mu \mathrm{s}$ & $81 \mathrm{~km}$ \\
\hline Subsequent strokes $(\mathrm{n}=124)$ & $162 \mu \mathrm{s}$ & $70 \mathrm{~km}$ \\
\hline
\end{tabular}

Notes: $r>100 \mathrm{~km}$; the standard errors of mean values of $h_{1}$ are less than $2 \%$ of the mean.

These results are presented by Haddad et al. (2012) [17].

\section{X-RAYs Produced by First AND SUbSEQUent STROKES IN NATURAL LIGHTNING}

On July 31, 2011, we recorded 23 strokes (8 first and 15 subsequent) within $2 \mathrm{~km}$ of LOG. Out of the 23 strokes, 11 produced x-ray bursts, 3 produced single x-ray pulses, and 9 did not produce detectable $\mathrm{x}$-ray emissions (with at least 128 $\mathrm{keV}$ energy) during $2 \mathrm{~ms}$ prior to and $10 \mu \mathrm{s}$ after the beginning of return stroke. The x-ray burst was defined as a sequence of two or more pulses (not necessarily a single photon per pulse, as discussed below). The occurrence of x-rays was $88 \%$ and $47 \%$ for first and subsequent strokes, respectively.

The occurrence of $\mathrm{x}$-rays tends to increase with increasing return-stroke peak current and decreasing distance from the lightning channel, as illustrated by Tables IV and V, respectively. Both these dependences are expected: the returnstroke peak current is thought to be correlated with leader tip electric potential (the higher the potential, the stronger the $\mathrm{x}$ ray source), and larger distances are associated with stronger $\mathrm{x}$ ray absorption and scattering. It is worth noting that the observed trends are each characterized by large scatter and that the sample size is small (only 23 strokes). For these reasons, we do not attach much significance to the percentages given in Tables IV and V.

Not all strokes within the same flash produced x-rays, and 5 out of 7 subsequent-stroke leaders produced more x-ray pulses than their corresponding first-stroke leaders. The latter observation means that dart and dart-stepped leaders can be more prolific x-ray producers than their corresponding stepped leader, an observation which has not been reported before. Examples are shown in Figs. 8 and 9, where NLDN-reported distances (r) and peak currents (I), as well as leader durations (LD) are indicated.

In Fig. 8, out of five strokes recorded at LOG, only three (of order 1, 3, and 5) produced detectable x-rays. Although the NLDN-reported distances to the five strokes ranged from 0.9 to $1.4 \mathrm{~km}$, these strokes probably occurred in the same channel. This is because all subsequent-leader durations were of the order of hundreds of microseconds, which is indicative of dart or very fast dart-stepped leaders (e.g., Rakov and Uman, 1990) [20]. It appears from the non-detection of X-rays during strokes 2 and 4, while strokes 1,3 , and 5 (presumably in the same channel) produced pronounced $\mathrm{x}$-ray bursts, that the runaway breakdown (the only viable source of $\mathrm{x}$-rays) is not a necessary feature of lightning leaders.

TABLE IV. OCCURRENCE OF X-RAYS AS A FunCTION OF RETURN-STROKE PEAK CURRENT. ADAPTED FROM [21].

\begin{tabular}{|c|c|c|c|}
\hline $\begin{array}{c}\text { Peak current } \\
\text { range (kA) }\end{array}$ & $\begin{array}{c}\text { Number of } \\
\text { strokes }\end{array}$ & $\begin{array}{c}\text { Number of strokes } \\
\text { with x-rays }^{\mathbf{1}}\end{array}$ & Percentage \\
\hline $10-20$ & 5 & $2(2+0)$ & $40 \%$ \\
\hline $20-40$ & 13 & $7(4+3)$ & $54 \%$ \\
\hline $40-60$ & 5 & $5(5+0)$ & $100 \%$ \\
\hline $10-60$ & 23 & $14(11+3)$ & $61 \%$ \\
\hline
\end{tabular}

${ }^{1}$ The first and second numbers in the parentheses indicate the occurrence of x-ray bursts and single pulses, respectively.

TABLE V. OCCURRENCE OF X-RAYS AS A FUNCTION OF DISTANCE FROM THE LigHTNING CHANNEL. ADAPTED FROM [21].

\begin{tabular}{|c|c|c|c|}
\hline $\begin{array}{c}\text { Distance } \\
\text { range } \mathbf{( k m )}\end{array}$ & $\begin{array}{c}\text { Number of } \\
\text { strokes }\end{array}$ & $\begin{array}{c}\text { Number of strokes } \\
\text { with } x-\text {-rays }^{1}\end{array}$ & Percentage \\
\hline $0.5-1$ & 11 & $9(7+2)$ & $82 \%$ \\
\hline $1-1.5$ & 9 & $4(3+1)$ & $44 \%$ \\
\hline $1.5-2$ & 3 & $1(1+0)$ & $33 \%$ \\
\hline $0.5-2$ & 23 & $14(11+3)$ & $61 \%$ \\
\hline
\end{tabular}

${ }^{1}$ The first and second numbers in the parentheses indicate the occurrence of x-ray bursts and single pulses, respectively. 
Flash 3835
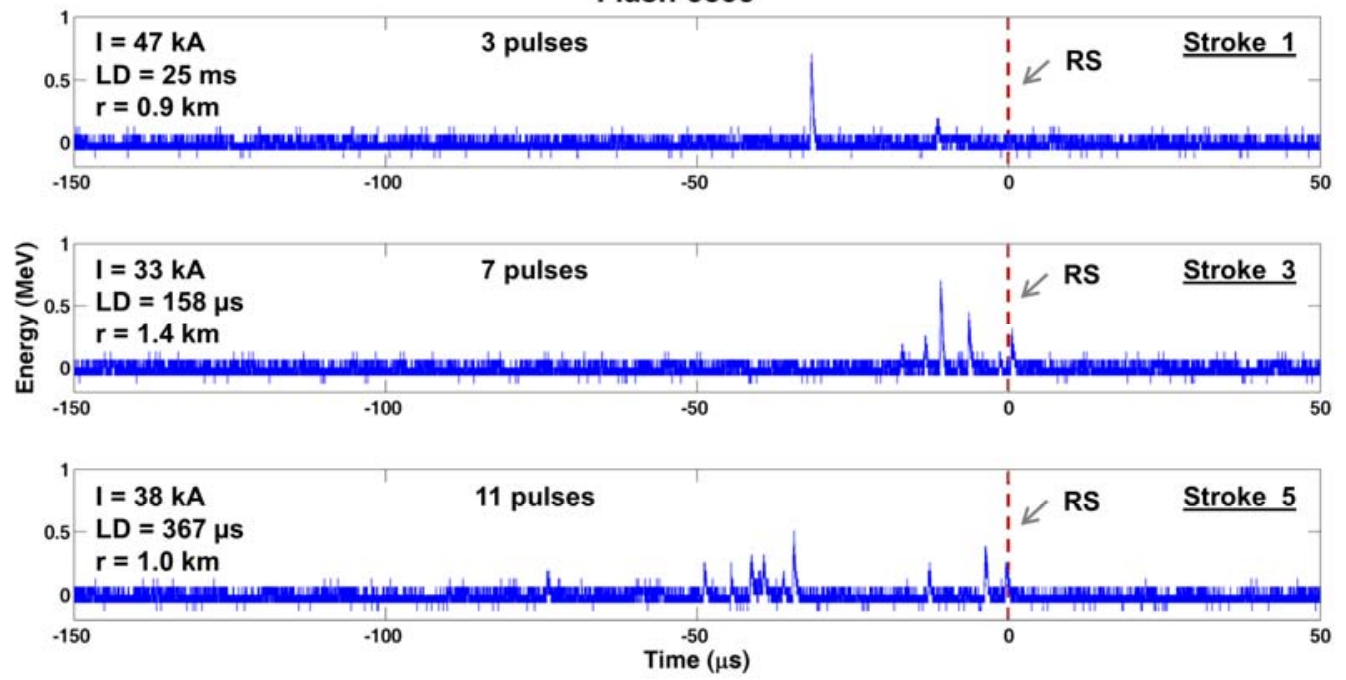

Figure 8. X-rays produced by stroke 1 (top), stroke 3 (middle), and stroke 5 (bottom) of 11-stroke flash 3835 . Strokes 2 and 4 did not produce detectable x-rays. Strokes 6 to 11 were not recorded at LOG. NLDN-reported distances for strokes 1 to 5 were 0.9 to $1.4 \mathrm{~km}$. Vertical broken lines labeled RS indicate the position of the return stroke. Judging from leader durations (LD), strokes 3 and 5 each followed a previously formed channel. Adapted from [21].

\section{Flash 3832}
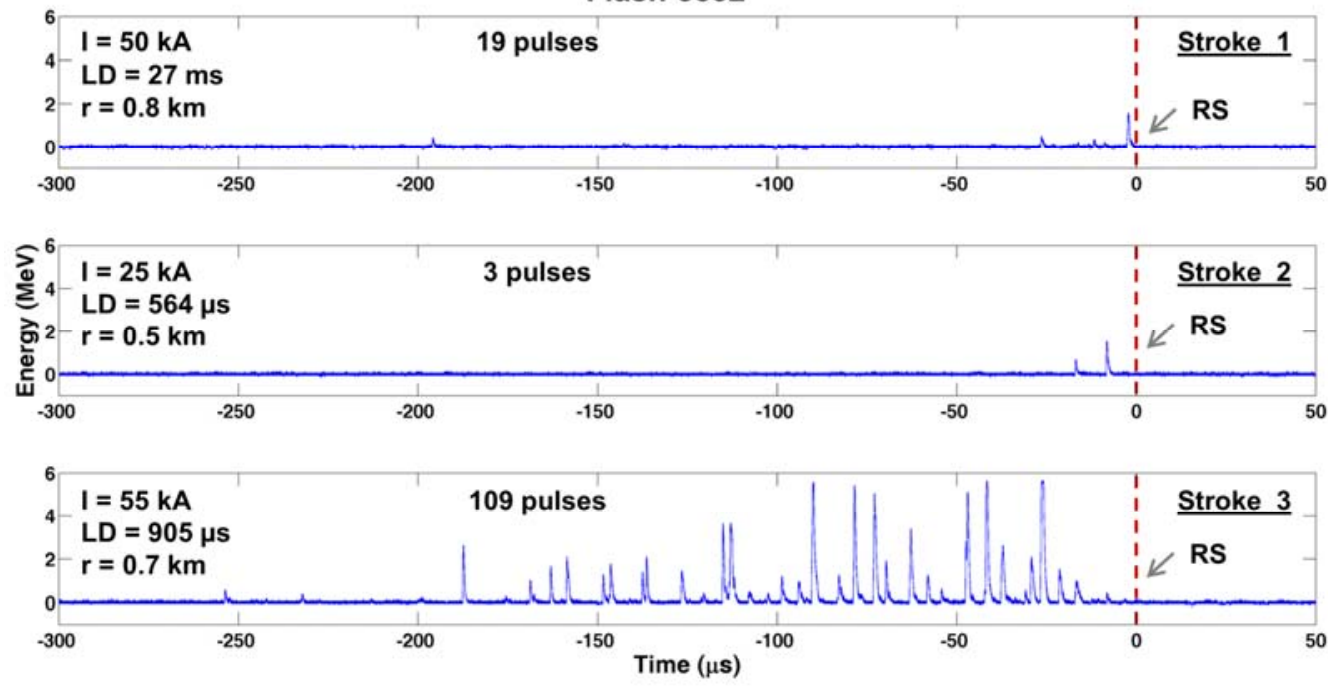

Figure 9. X-rays produced by stroke 1 (top), stroke 2 (middle), and stroke 3 (bottom) of 13-stroke flash 3832 . Strokes 4 to 13 were not recorded at LOG. NLDNreported distances for strokes 1 to 3 were 0.5 to $0.8 \mathrm{~km}$. Vertical broken lines labeled RS indicate the position of the return stroke. Some pulses seen in the plots are due to multiple photons arriving within the response time of the $\mathrm{x}$-ray detector; that is, are actually each a superposition (pile-up) of two or more individual pulses. There are a total of 22 such pile-ups, 3 of which are clipped at $5.6 \mathrm{MeV}$ level. All discernible individual pulses are included in the pulse count given on the plots. Adapted from [21].

Further, subsequent-stroke leaders shown in Fig. 8 appeared to produce more $\mathrm{x}$-ray pulses ( 7 and 11) than their corresponding first-stroke leader (only 3 detectable x-ray pulses). It is important to note that some pulses seen in Figs. 8 and 9 are due to multiple photons arriving within the response time (about $1 \mu \mathrm{s}$ ) of the x-ray detector; that is, are actually each a superposition (pile-up) of two or more individual pulses. All discernible individual pulses are included in the pulse count given in Figs. 8 and 9.
In Fig. 9, all three strokes recorded at LOG produced $\mathrm{x}-$ rays, but the third stroke was much more prolific x-ray producer (a total of 109 discernible pulses) than the other two strokes (19 and 3 pulses). Note that all three strokes apparently occurred in the same channel, and that peak currents for strokes 1 and 3 were similar (50 and $55 \mathrm{kA}$, respectively). This latter observation is important, since it apparently supports the theory (Cooray et al., 2009, 2010) [22,23], according to which a warm, low-density channel traversed by subsequent-stroke 
leaders is more conducive to occurrence of the so-called cold runaway breakdown than the virgin air in which first-stroke leaders have to develop.

These results are presented by Mallick et al. (2012b) [21].

\section{CONCLUDING REMARKS}

The Lightning Observatory in Gainesville (LOG), Florida, has been continuously operated since 2004. The results of observations at LOG have provided considerable insight into lightning properties and mechanisms. Among important findings are inferences on the role of lower positive charge region in the cloud in facilitating different types of lightning, characterization of positive lightning flashes in Florida, discovery of the mechanism of electromagnetic radiation of compact intracloud discharges and estimation of their electrical parameters, new inferences on the interaction of lightning electromagnetic pulse with the ionosphere, and production of $\mathrm{x}$-rays by first- and subsequent-stroke leaders.

\section{ACKNOWLEDGMENT}

The authors would like to thank B.A. DeCarlo, D. Tsalikis, M.A. Haddad, V.B. Somu, and R.C. Olsen III for their help with building electronics and data acquisition and processing. Also acknowledged is collaboration with S.A. Cummer and J.R. Dwyer on the ionosphere and X-ray projects, respectively. NLDN data were provided by Vaisala (J.A. Cramer).

\section{REFERENCES}

[1] A. Nag, "Characterization and modeling of lightning processes with emphasis on compact intracloud discharges", Ph.D. dissertation, University of Florida, Gainesville, FL, USA, 2010.

[2] S. Mallick, V. A. Rakov, A. Nag, C. Biagi, D. Hill, D. M. Jordan, and M. A. Uman, "Measurements of radiation field signatures of rockettriggered lightning”, J. High Volt. Eng., China, 2012a (under review).

[3] A. Nag, and V.A. Rakov, "Pulse trains characteristic of preliminary breakdown in cloud-to-ground lightning that are not followed by return stroke pulses", J. Geophys. Res., 113, D01102, J. Geophys. Res., 113, D01102, doi:10.1029/2007JD008489, 2008.

[4] A. Nag, and V.A. Rakov, "Some inferences on the role of lower positive charge region in facilitating different types of lightning", Geophys. Res. Lett., 36, L05815, doi:10.1029/2008GL036783, 2009a.

[5] A. Nag, and V.A. Rakov, "Electric field pulse trains occurring prior to the first stroke in cloud-to-ground lightning", IEEE Trans. EMC, 51(1), 147-150, doi:10.1109/TEMC.2008.2005488, 2009b.

[6] A. Nag, and V. A. Rakov, "Positive lightning: An overview, new observations, and inferences", J. Geophys. Res., 117, D08109, doi:10.1029/2012JD017545, 2012.

[7] M. Ishii, K. Shimizu, J. Hojo, and K. Shinjo, "Termination of multiplestroke flashes observed by electromagnetic field", Proc. 24th Int. Conf. on Lightning Protection, Birmingham, U.K., Staffordshire University, pp. 11-16, 1998.

[8] S. A. Fleenor, C. J. Biagi, K.L. Cummins, E. P. Krider, and X. M. Shao, "Characteristics of cloud-to-ground lightning in warm-season thunderstorms in the Central Great Plains", Atmos. Res., 91, 333-352, doi:10.1016/j.atmosres.2008.08.011, 2009.

[9] M. M. F. Saba, W. Schulz, T. A. Warner, L. Z. S. Campos, C. Schumann, E. P. Krider, K. L. Cummins, and R. E. Orville, "High-speed video observations of positive lightning flashes to ground", J. Geophys. Res., 115, D24201, doi:10.1029/2010JD014330, 2010.

[10] D. M. Le Vine, "Sources of the strongest RF radiation from lightning", J. Geophys. Res., 85(C7), 4091-4095, doi:10.1029/JC085iC07p04091, 1980.

[11] D. A. Smith, X. M. Shao, D. N. Holden, C. T. Rhodes, M. Brook, P. R. Krehbiel, M. Stanley, W. Rison, and R. J. Thomas, "A distinct class of isolated intracloud discharges and their associated radio emissions", J. Geophys. Res., 104(D4), 4189-4212, doi:10.1029/1998JD200045, 1999.

[12] A. Nag, and V.A. Rakov, "Electromagnetic pulses produced by bouncing-wave-type lightning discharges", IEEE Trans. on EMC, Special Issue on Lightning, 51(3), 466-470, doi:10.1109/TEMC.2009.2025495, 2009c.

[13] A. Nag, and V.A. Rakov, "Compact intracloud lightning discharges: 1 Mechanism of electromagnetic radiation and modeling", J. Geophys. Res., 115, D20102, doi:10.1029/2010JD014235, 2010.

[14] A. Nag, and V.A. Rakov, "Compact intracloud lightning discharges: 2. Estimation of electrical parameters”, J. Geophys. Res., 115, D20103, doi:10.1029/2010JD014237, 2010 .

[15] A. Nag, V.A. Rakov, D. Tsalikis, and J.A. Cramer, "On phenomenology of compact intracloud lightning discharges", J. Geophys. Res., 115, D14115, doi:10.1029/2009JD012957, 2010.

[16] A. Nag, V.A. Rakov, and J.A. Cramer, "Remote measurements of currents in cloud lightning discharges", IEEE Trans. EMC, 53(2), 407413, doi:10.1109/TEMC.2010.2073470, 2011.

[17] M. A. Haddad, V. A. Rakov, and S. A. Cummer, "New measurements of lightning electric fields in Florida: Waveform characteristics, interaction with the ionosphere, and peak current estimates", J. Geophys. Res., 117, D10101, doi:10.1029/2011JD017196, 2012.

[18] T.H. Laby, J.J. McNeill, F.G. Nicholls, and A.F.B. Nickson, "Wavefrom, energy and reflection by the ionosphere, of atmospherics," Proc. Roy. Soc., A174(957), 145-163, 1940.

[19] U.S. Inan, S.A. Cummer, and R.A. Marshall, "A survey of ELF and VLF research of lightning-ionosphere interactions and causative discharges", J. Geophys. Res., 115, A00E36, doi:10.1029/2009JA014775, 2010.

[20] V. A. Rakov, and M. A. Uman, "Waveforms of first and subsequent leaders in negative lightning flashes", J. Geophys. Res., 95(D10), 16561-16577, doi:10.1029/JD095iD10p16561, 1990.

[21] S. Mallick, V. A. Rakov, and J. R. Dwyer, "A study of x-ray emissions from thunderstorms with emphasis on subsequent strokes in natural lightning”, J. Geophys. Res., 2012b (under review).

[22] V. Cooray, M. Becerra, and V. A. Rakov, "On the electric field at the tip of dart leaders in lightning flashes", J. Atmos. \& Solar-Terr. Phys., 71(12), 1397-1404, doi:10.1016/j.jastp.2009.06.002, 2009

[23] V. Cooray, J. R. Dwyer, V. A. Rakov, and M. Rahman, "On the mechanism of x-ray production by dart leaders of lightning flashes", $\mathrm{J}$. Atmos. \& Solar-Terr. Phys., 72(11-12), 848-855, doi:10.1016/j.jastp.2010.04.006, 2010. 